\title{
EVALUATION OF PREDICTIVE FACTORS OF IN HOSPITAL MORTALITY IN PATIENTS WITH PROXIMAL FEMORAL FRACTURE
}

\author{
AVALIAÇÃO DE FATORES PREDITIVOS DA MORTALIDADE \\ INTRA-HOSPITALAR EM PACIENTES COM \\ FRATURA PROXIMAL DO FÊMUR
}

\author{
José Guilherme Lollo Correa ${ }^{1}$ (i), Fernando Brandão Andrade-Silva ${ }^{2}$ (i), Sileno Fortes Filho ${ }^{3}$ (i),

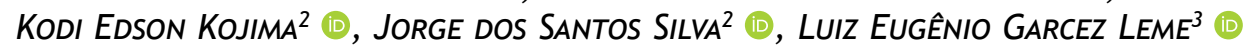 \\ 1. Universidade de São Paulo, Medical School, Institute of Orthopedics and Traumatology, São Paulo, SP, Brazil. \\ 2. Universidade de São Paulo, Medical School, Institute of Orthopedics and Traumatology, Trauma Group, São Paulo, SP, Brazil.
}

3. Universidade de São Paulo, Medical School, Institute of Orthopedics and Traumatology, Geriatrics Group, São Paulo, SP, Brazil.

\section{ABSTRACT}

Objective: To investigate the existence of a causal association between orthopedic treatment and the occurrence of in hospital death. Methods: 338 patients with proximal femoral fracture were evaluated, of whom 27 faced in hospital death. Patients who faced in hospital death (case group) were compared to patients who did not (control group) regarding exposure to risk factors prior to injury and factors related to orthopedic treatment. Results: The factors related to higher in hospital mortality rate were: male sex (case group: $52 \%$, control: $26 \% ; p=0.005$ ), lower Parker's score (case group: 5.0 points, control: $6.2 ; p=0.048$ ), delirium on admission (case group: $26 \%$, control: $10 \%$; $p=0.011$ ); delirium developed during hospitalization (case group: $77 \%$, control: 35\%; $p<0.001$ ), and time until surgery (13.3 days, 9.1; $p=0.049)$. Conclusion: The in hospital mortality rate of patients with proximal femoral fracture was $8 \%$, and the main associated risk factors were male sex, reduced Parker's score, delirium diagnosed on hospital admission or developed during hospitalization, and time until surgery. Level of Evidence III, Case control study.

Keywords: Fractures, Bone. Femur. Mortality. Delirium.

\section{RESUMO}

Objetivo: Pesquisar a existência de associação causal entre fatores do tratamento ortopédico e a ocorrência de morte intra-hospitalar. Métodos: Foram avaliados 338 pacientes com fratura proximal do fêmur, dos quais 27 apresentaram óbito intra-hospitalar. Compararam-se pacientes que apresentaram óbito intra-hospitalar (grupo caso) com pacientes que não apresentaram óbito hospitalar (grupo controle) quanto à exposição a fatores de risco prévios à lesão e fatores relacionados ao tratamento ortopédico. Resultados: Os fatores relacionados a uma maior taxa de mortalidade intra-hospitalar foram: gênero masculino (grupo caso: $52 \%$; controle: $26 \%$; $p=0,005)$, menor escore de Parker (grupo caso: 5,0 pontos; controle: 6,2 pontos; $p=0,048$ ), delirium na admissão (grupo caso: $26 \%$; controle: $10 \% ; p=0,011$ ); delirium desenvolvido durante a internação (grupo caso: 77\%; controle: $35 \%$; $p<0,001$ ), e tempo até a cirurgia (13,3 dias vs. 9,1 dias; $p=0,049$ ). Conclusão: No presente estudo, a taxa de mortalidade intra-hospitalar em pacientes com fratura proximal do fêmur foi de $8 \%$, e os principais fatores de risco associados a esse desfecho foram o gênero masculino, escore de Parker reduzido, delirium diagnosticado na admissão hospitalar ou desenvolvido durante a internação, e tempo até a cirurgia. Nível de Evidência III, Estudo caso controle.

Descritores: Fraturas Ósseas. Fêmur. Mortalidade. Delirium.

Citation: Correa JGL, Andrade-Silva FB, Fortes Filho S, Kojima KE, Silva JS, Leme LEG. Evaluation of predictive factors of in hospital mortality in patients with proximal femoral fracture. Acta Ortop Bras. [online]. 2020;28(1):40-3. Available from URL: http://www.scielo.br/aob.

\section{INTRODUCTION}

The frequency of fractures of the proximal extremity of the femur increased significantly in recent decades. This is believed to be directly related to the increase in the older population in our society, given that this disease occurs mainly in older patients and with progressive incidence as age advances. ${ }^{1}$

In Brazil, in 2015, 47,000 femoral fractures were recorded among older adults. ${ }^{2}$ We believe this number is even higher, given the low notification of diseases by public and private health services.

This fracture is strongly related to mortality and functional loss since the main affected population are patients with multiple comorbidities and high risk of postoperative complications. A recent data assessment with 91,401 patients with femur fracture in the United States identified hospital mortality rates of $1.8 \%, 11 \%$ for rehospitalization within 30 days, and $10.4 \%$ for early sequelae

All authors declare no potential conflict of interest related to this article.

Study was conducted at the Universidade de São Paulo, Medical School, Institute of Orthopedics and Traumatology, São Paulo, SP, Brazil. Correspondence: Jose Guilherme Lollo Correa. Rua Dr. Ovídio Pires de Campos, 333, São Paulo, SP, Brazil, 05403010. guilhermelollo@gmail.com 
(venous thromboembolism, pressure ulcers, and pneumonia within 30 days). ${ }^{3}$ The risk of death remains even after hospital discharge; however, mortality rates varied greatly in the literature consulted. A study conducted in Brazilian hospital in 2007 observed mortality of up to $36 \% 24$ months after fracture, and $60 \% 48$ months after the occurrence. ${ }^{4}$ Another study conducted in Rio de Janeiro in 2009 identified $28.7 \%$ as the mortality rate in the first year after hip fracture in patients. ${ }^{5}$

Although the causes for the high mortality of older patients with fracture on the proximal extremity of the femur have been well-documented in developed countries, little is known about this subject in developing countries. There is no consensus among the scientific literature when studying the existence of an association between waiting time for surgical treatment and mortality of these patients. The risk of in hospital death after proximal femoral fracture has been associated with the patient's prior clinical condition and cardiovascular risk factors. However, the in hospital mortality rate changes in the literature and risk factors are inconsistent between different studies. ${ }^{6}$ The descriptive analysis of patients who suffer in hospital death and the identification of risk factors for this event may help in decision making for the treatment of this fracture and in the adoption of preventive measures.

The primary objective of this study is to investigate the existence of a causal association between factors of orthopedic treatment, including waiting time for surgery, type of surgery and time of surgery, and the occurrence of in hospital death. Our secondary objectives are to study the association between in hospital mortality and demographic characteristics, characteristics of the fracture and clinical risk factors.

\section{METHODS}

\section{Study design}

This is an observational study that assessed risk factors for in hospital mortality after proximal femoral fracture in older adults. The study was approved by the Research Ethics Committee of our Institution (66729616100000068) The data in this study come from a prospective cohort study previously conducted in the same institution - the analyzed cases did not sign the informed consent form -, that evaluated the predictive factors of mobility and mortality in older adults with proximal femoral fracture for 12 months.

In total, 338 patients were included, 27 of whom died in hospital. This study compared patients who presented in hospital death (case group) to patients who did not (control group) regarding the exposure to previous risk factors to the injury, and factors related to the orthopedic treatment. The objective is to verify a possible causal association between the evaluated factors and the occurrence of in hospital death.

\section{Casuistry}

This study included all patients evaluated on the previously cited prospective cohort, which used the following selection criteria:

- Inclusion: Patients aged 60 years or older, hospitalized in our service due to proximal femoral fracture from June 2014 to January 2017; having indication of surgical treatment at the time of hospitalization.

- Exclusion: Impossibility of telephone contact for patient follow-up and measurement of outcomes, refusal to participate in the study, severe hearing deficit, and not speaking the Portuguese language.

\section{Analyzed exposure factors}

The following variables will be compared between the case and control groups to assess the risk of in hospital death, being divided into the following categories:

- Demographic data and fracture characteristics: age; sex; ethnicity; type of fracture (femur neck, transtrochanteric, subtrochanteric);
- Clinical risk factors: existence of a previous fracture; comorbidities (systemic arterial hypertension, diabetes, congestive heart failure, coronary heart disease, stroke, kidney failure, pulmonary disease, cancer, dementia, depression, smoking, and alcoholism); "10-point Cognitive Screener" scale for delirium detection; Parker's mobility score; fall history in the past year; weight loss in the last month; ASA score; cardiovascular risk; existence of delirium on admission; delirium developed during hospitalization; type of delirium (hypoactive, hyperactive, mixed).

Parker's score evaluates the mobility of patients prior to a fracture in their own home, away from home and when shopping. Each step ranges from 0 to 3 points - total score ranges from 0 to 9 points, and the higher the score, the better the mobility. Participants who cannot walk score zero; those who walk only with the help of another person score one; those who walk with the help of an instrument (cane, walker) score two; and those who walk normally, without any help score three? - Factors related to orthopedic treatment: time between admission and surgery; type of surgery; surgery time; intraoperative intercurrence.

\section{Sample calculation and statistical analysis}

No specific sample calculation was performed for this study. The sample size was defined by previously collected data in the prospective cohort.

Descriptive statistical analysis of the variables listed above was performed using absolute numbers and percentages for categorical variables, and by the mean and standard deviation for quantitative variables. The proportion of categorical variables was compared between the groups using the Chi-square test or Fisher's test, according to the number of observations in each group, to calculate the odds ratio (OR). Quantitative variables were compared between groups by Student's t-test or Mann-Whitney's test, when presenting parametric or non-parametric distribution, respectively. Possible confounding variables that could be related to both the exposure factor and outcome were analyzed through univariate regression analysis. The stratified comparison between groups was performed if confounding variables existed. All tests were two-tailed, and statistical significance was considered when $p<$ 0.05 . The analyses were performed with the software Stata version 13.1 (StataCorp, College Station, TX).

\section{RESULTS}

Initially, 338 individuals were selected. Of these, 8 were discarded due to presenting incomplete or missing data in the medical records. The sample for our study was thus 330 patients. They were separated into two groups: those who presented in hospital death (control), and those who did present in hospital death during hospitalization (case)

Table 1 shows the characteristics of this sample and the comparison between the patient's sex, ethnicity, presence of previous fracture, dementia, number of medications, Parker's score, time until surgery, delirium on admission, and delirium at any time during hospitalization between the case and control groups. Statistical significance was observed in the analysis of sex, Parker's score, time until surgery, delirium on admission, and delirium at any time during hospitalization.

The topography of the fracture $(p=0.981)$, ethnicity $(p=0.797)$, history of previous fracture $(p=0.133)$, dementia $(p=0.210)$, and the number of medications used by patients $(p=0.143$ ) were not statistically significant factors for the increase in in hospital mortality. Sex showed a clear statistical difference regarding the outcome. Although only $28 \%$ of the patients were male, the in hospital mortality of this population was $17.5 \%$, whereas the mortality of females was $5.8 \%(p=0.05)$. 
Table 1. Comparison between the case and control groups considering risk factors.

\begin{tabular}{|c|c|c|c|c|}
\hline & CONTROL $(n=303)$ & CASE $(n=27)$ & Total $(n=330)$ & P-value \\
\hline Age & $80.1(9.2)$ & $82.6(10.1)$ & $80.3(9.3)$ & 0.184 \\
\hline Sex & & & & 0.005 \\
\hline Male & $80(26 \%)$ & $14(52 \%)$ & $94(28 \%)$ & \\
\hline Type of Fracture & & & & 0.981 \\
\hline Femur neck & $129(43 \%)$ & $11(40 \%)$ & $140(43 \%)$ & \\
\hline Others & $14(5 \%)$ & $1(4 \%)$ & $15(5 \%)$ & \\
\hline Ethnicity & & & & 0.797 \\
\hline White & $246(81 \%)$ & $23(85 \%)$ & $269(82 \%)$ & \\
\hline Non-white & $57(19 \%)$ & $4(15 \%)$ & $61(18 \%)$ & \\
\hline Previous fracture & $91(30 \%)$ & $12(44 \%)$ & $103(31 \%)$ & 0.133 \\
\hline Delirium on admission & $30(10 \%)$ & $7(26 \%)$ & $37(11 \%)$ & 0.011 \\
\hline Delirium during hospitalization & $106(35 \%)$ & $20(77 \%)$ & $126(38 \%)$ & $<0.001$ \\
\hline
\end{tabular}

Parker's score was also a statistically significant for the patients' death outcome ( $p=0.048)$. The mean for Parker's score for the control group was 6.2 (2.8), and for the case group it was 5.0 (3.1) ( $p=0.048$ ). Delirium on hospital admission proved to be another factor of worse prognosis for older adults with proximal femoral fracture $(p=0.011)$. Among the patients in the case group ( $n=27), 7(26 \%)$ of them presented delirium on admission. On the other hand, the control group presented only $10 \%$ of delirium on admission. Delirium at any time during hospitalization - whether at admission or developed within the hospital environment - was another predictive factor for the outcome of death ( $p<0.001$ ). In the case group, $77 \%$ of the patients presented delirium at some point in their hospitalization, contrasting with only $35 \%$ of patients who presented delirium from the control group. Finally, the waiting time until the surgical procedure was another statistically relevant factor $(p=0.049)$ for the outcome difference between the case and control groups. In the control group, the mean waiting time for surgical treatment was 9.1 (17.3) days, in the control group the waiting time was 13.3 (16.6) days.

\section{DISCUSSION}

In this study, we showed the existence of factors that cause a worse prognosis for the occurrence of in hospital mortality in older patients with proximal femoral fracture. According to our data, male patients, with 5 mean Parker's score, and presented delirium on admission or during hospitalization have greater risk of presenting in hospital death. The time until surgery also presented an association with in hospital death; however, this variable depends on other factors such as the existence of clinical comorbidities, and should be interpreted with caution in the analysis of the risk of in hospital death. The data from this study may assist in decision making regarding the choice of treatment and in defining the prognosis of patients with proximal femoral fracture.

Regarding the demographic analysis, patients who suffered proximal femoral fracture were females (72\%). Similar results were observed in a retrospective study in the Lazio region with 8,896 patients - of which $78 \%$ were women among the older adults hospitalized with proximal femoral fracture -, and the higher rate of in hospital mortality was observed for men when compared to women. ${ }^{8}$ Paksina et al. ${ }^{9}$ found that men are at $41 \%$ risk of death outcome. Kannegard et al. ${ }^{10}$ found that being male is a strong risk factor for death after proximal femoral fracture. According to the authors' opinion, such higher mortality may be related to undiagnosed or undertreated comorbidities in this group, leading to more severe and potentially fatal postoperative complications.

In this study, delirium was an important factor for the worse prognosis and mortality among patients. Dubljanin Raspopovic E. et al. ${ }^{11}$ followed, for 30 days, the postoperative period of patients with proximal femoral fracture and observed that $6.4 \%$ died. Postoperative delirium was the only independent variable related to mortality within 30 days of the fracture in their study. Moreover, male older patients with worse cognitive status had a higher chance of developing postoperative delirium. The identification of patients at risk of developing postoperative delirium at admission and the early detection of delirium enables the development of targeted prevention and intervention strategies in older patients with hip fracture.

Although most of the literature finds similar results regarding delirium and mortality of older adults with proximal femoral fracture, Juliebø $V$ et al. ${ }^{12}$ contradicts such finding. Delirium presented no association when adjusted for the severity of the chronic cognitive impairment measured by the Informant Questionnaire for Cognitive Decline in the Elderly. In 1993, Parker MJ et al. ${ }^{7}$ presented a new score for the evaluation of mobility pre-proximal femoral fracture and a mental test score to determine what was the most important value in predicting mortality within a year. Both scores provided a highly significant prediction, but the mobility score had a higher predictive value. In the our study, Parker's score also proved to be a predictive factor for in hospital mortality of patients with proximal femoral fracture. Kristensen MT et al. ${ }^{13}$ showed that patients with proximal femoral fracture who died in the hospital environment had a lower functional level before the fracture when compared to those who were discharged. This study thus corroborates the literature in this regard, showing the need for a good preoperative evaluation for better surgical programming and postoperative care of patients with worse status-performance before the fracture.

The $8.1 \%$ mortality during hospitalization found by our study was higher than that cited by Sakaki et $a .^{14}$ in a review article, in which the authors stress that the incidence of deaths in older adults with proximal femoral fracture is significantly higher than in the general older adult groups. In their study, the factors identified as closely 
related to higher mortality were, among others, males and the presence of cognitive impairments, similar to our study. The authors also showed a correlation, although weak, between the prior walking capacity and the increase in mortality of these patients, which was also observed in our study. However, Sakaki et al. ${ }^{14}$ observed that the time before the surgery did not interfere with mortality, contrary to data from our study and other previous studies.

The mean waiting time for surgery since admission in our study was 9.4 days, shorter than the one found by Souza et al. (14.8 days). ${ }^{15}$ Although this association has been identified in the literature, ${ }^{16,17}$ there is no consensus on the role of waiting time to be operated on the chance of death. In our study, the waiting time for surgery had a significant correlation with the final outcome death in the hospital environment ( $p=0.049$ ); however, as previously discussed, this data may not represent a direct causal factor for mortality, and may be consequence of other variables such as the presence of clinical comorbidities that contraindicate surgical treatment.

The main favorable points of this study were the broad casuistry and prospective data collection in a controlled environment (with retrospective data analysis), which ensured the good internal validity of the study. Similarly, external validity was adequate, evaluating fracture patterns and common treatment methods in orthopedic practice. Therefore, the data in this study can be generalized to the general population. As the main limitations, we can cite the limited number of patients with the outcome of interest (in hospital death), making a broader statistical analysis impossible, e.g., including the risk rates of the identified variables. Due to the heterogeneity of patients and the observational character of the study, we cannot state specific recommendations regarding the indication of surgical or non-surgical treatment based only on the data in this study.

\section{CONCLUSIONS}

Hospitalized older adults with proximal femoral fracture had an 8\% in hospital mortality rate. The main risk factors for in hospital death were male sex, low previous functional capacity indicated by a reduced Parker's score, delirium diagnosed at hospital admission or developed during hospitalization, and a longer waiting time until surgery.

AUTHORS' CONTRIBUTIONS: Each author contributed individually and significantly to the development of the manuscript. JGLC and FBAS were the main contributors to the writing of the manuscript. SFF and LEGL analyzed the medical records and collected data. JSS evaluated the data from the statistical analysis. KEK performed the bibliographic research, reviewed the manuscript, and contributed to the intellectual design of the study.

\section{REFERENCES}

1. Arliani GG, Astur DC, Linhares GK, Balbachevsky D, Fernandes HJA, Reis FB Correlação entre tempo para o tratamento cirúrgico e mortalidade em pacientes idosos com fratura da extremidade proximal do fêmur. Rev Bras Ortop. 2011;46(2):189-94. doi: 10.1590/S0102-36162011000200013

2. Daniachi D, Santos A Netto, Ono NK, Guimarães RP, Polesello GC, Honda EK. Epidemiologia das fraturas do terço proximal do fêmur em pacientes idosos. Rev Bras Ortop [Internet]. 2015 [cited 2017 Nov 20];50(4):371-7. Available from: http://bit.ly/2p6eN2N

3. Leme LEG, Sguizzatto GT. Profilaxia do tromboembolismo venoso em cirurgia ortopédica. Rev Bras Ortop [Internet]. 2012 [cited 2017 Nov 20];47(6):685-93. Available from: http://bit.ly/2BDFRce

4. Guerra MTE, Viana RD, Feil L, Feron ET, Maboni J, Vargas AS-G. Mortalidade em um ano de pacientes idosos com fratura do quadril tratados cirurgicamente num hospital do Sul do Brasil. Rev Bras Ortop [Internet]. 2017 [cited 2017 Nov 20];52(1):17-23. Disponível em: http://bit.ly/2JdRfQi

5. Ricci G, Longaray MP, Gonçalves RZ, Ungaretti AS Neto, Manente M, Barbosa LBH. Avaliação da taxa de mortalidade em um ano após fratura do quadril e fatores relacionados à diminuição de sobrevida no idoso. Rev Bras Ortop [Internet]. 2012 [cited 2017 Nov 20];47(3):304-9. Available from: http://bit.ly/2BFAeu0

6. Franco LG, Kindermann AL, Tramujas L, Kock KS. Fatores associados à mortalidade em idosos hospitalizados por fraturas de fêmur. Rev Bras Ortop [Internet]. 2016 [cited 2017 Nov 20];51(5):509-14. Available from: http://bit.ly/368SpGO

7. Parker MJ, Palmer CR. A new mobility score for predicting mortality after hip fracture. J Bone Joint Surg Br [Internet]. 1993 [cited 2018 Aug 15];75(5):797-8. Available from: http://bit.ly/2MHNogo

8. Castronuovo E, Pezzotti P, Franzo A, Di Lallo D, Guasticchi G. Early and late mortality in elderly patients after hip fracture: a cohort study using administrative health databases in the Lazio region, Italy. BMC Geriatr [Internet]. 2011 [cited 2018 Aug 15];11:37. Available from: http://bit.ly/31KE5kt
9. Paksima N, Koval KJ, Aharanoff G, Walsh M, Kubiak EN, Zuckerman JD, et al. Predictors of mortality after hip fracture: a 10-year prospective study. Bull NYU Hosp Jt Dis [Internet]. 2008 [cited 2018 Aug 15];66(2):111-7. Available from: http://bit.ly/2MDdOjv

10. Kannegaard PN, van der Mark S, Eiken P, Abrahamsen B. Excess mortality in men compared with women following a hip fracture: National analysis of comedications, comorbidity and survival. [Internet]. 2010 [cited 2018 Aug 15];39(2):203-9. Available from: http://bit.ly/2qFR1Lx

11. Dubljanin Raspopovic E, Markovic Denic L, Marinkovic J, Radinovic K, llić N, Tomanović Vujadinović S, et al. Early mortality after hip fracture: what matters? Psychogeriatrics. 2015;15(2):95-101.

12. Juliebø V, Krogseth M, Skovlund E, Engedal K, Ranhoff AH, Wyller TB. Delirium is not associated with mortality in elderly hip fracture patients. Dement Geriatr Cogn Disord. 2010;30(2):112-20.

13. Kristensen MT, Foss NB, Ekdahl C, Kehlet $\mathrm{H}$. Prefracture functional level evaluated by the New Mobility Score predicts in-hospital outcome after hip fracture surgery. Acta Orthop [Internet]. 2010 [cited 2018 Aug 15];81(3):296-302. Available from: http://bit.ly/31GnIVG

14. Sakaki MH, Oliveira AR, Coelho FF, Leme LEG, Suzuki I, Amatuzzi MM. Study of the proximal femoral fractures mortality in elderly patients. Acta Ortop Bras [Internet]. 2004 [cited 2018 Aug 15];12(4):242-9. Available from: http://bit.ly/31zerio

15. Souza RC, Pinheiro RS, Coeli CM, Camargo KR Jr, Torres TZG. Aplicação de medidas de ajuste de risco para a mortalidade após fratura proximal de fêmur. Rev Saúde Pública [Internet]. 2007 [cited 2018 Aug 15];41(4):625-31. Available from: http://bit.ly/31Gq72E

16. Morghen S, Gentile S, Ricci E, Guerini F, Bellelli G, Trabucchi M. Rehabilitation of older adults with hip fracture: cognitive function and walking abilities. J Am Geriatr Soc. 2011;59(8):1497-502.

17. Casaletto JA, Gatt R. Post-operative mortality related to waiting time for hip fracture surgery. Injury. 2004;35(2):114-20. 